\title{
Is it time to reconsider the role of patient co-payments for pharmaceuticals in Europe?
}

\author{
Michael Drummond • Adrian Towse
}

Published online: 26 October 2011

(C) Springer-Verlag 2011

\section{The chequered history of co-payments}

There are two general purposes of co-payments in health insurance systems, whether public or private. The first is to deal with the problem of moral hazard. Economic theory [1] tells us that to be efficient, health insurance cannot offer $100 \%$ coverage, so reducing the marginal cost faced by the patient to zero. The patient and their agent (the doctor) will consume health care until there is zero benefit, i.e. want all care that is effective irrespective of cost. Chalkley and Robinson [2] refer to this as the micro-efficiency challenge. Spreading risk has to be balanced by some co-payment. ${ }^{1}$ The second purpose is revenue raising, which can be thought of as seeking to reduce the cost to the third-party payer $^{2}$ not by cutting use but by raising offsetting funds. Patients get the health care but the burden on the insurer is lower.

There is of course a tension between these two objectives. If demand is inelastic then moral hazard is low and the co-payment will raise money. Conversely, if demand is elastic then co-payment will have a big impact on utilisation and little revenue will be raised. Of course, if the purpose is simply to reduce cost to the third-party payer by

M. Drummond $(\square)$

Centre for Health Economics, University of York, Alcuin A Block, Heslington, York YO10 5DD, UK e-mail: md18@york.ac.uk

\section{A. Towse}

Office of Health Economics, London, UK whatever means then either route is acceptable-lower utilisation or reduction in cost net of patient contributions.

However, evidence suggests that co-payments are inequitable. If you make people pay then poor people do not take their medicine. Evidence from RAND Health Insurance experiment [3] found that as the level of cost sharing for healthcare services increases so utilisation (in terms of probability of medicine use, inpatient stays, admissions and outpatient visits) falls. Cost sharing reduced utilisation without regard for effectiveness. The impact on the utilisation of effective as well as medically inappropriate treatments was similar. Cost sharing was linked to poorer health outcomes and the impact on utilisation was greatest on groups with lower incomes. Therefore, both micro-efficiency and equity are harmed. Literature reviews in the 1990s [4-6] and in the last decade $[7,8]$ have all confirmed the key findings of the RAND study.

Patient co-payments have, therefore, never been very popular with health economists from countries with socialised health care, because of their expected negative impacts on equity, without corresponding benefits in terms of increased efficiency. Writing on the use of user charges in the Canadian healthcare system, Barer et al. [9] concluded as long ago as 1979 that 'There is ... no support for any presumption that direct charges are a 'good thing'. In fact, the deck seems to be stacked against their successful deployment as a cost control mechanism or as a policy intended to help achieve other reasonable social program

\footnotetext{
${ }^{1}$ We use the term co-payment and co-insurance interchangeably. They are both patient payments that reduce the coverage provided by the third-party payer.

2 The term "macro-efficiency" is used for the related, but separate, issue of whether overall health system expenditure growth is reduced by cost sharing.
} 
objectives. ... 'It appears that the direct charge concept is indeed an idea whose time has gone., 3

The central argument against the moral hazard case for co-payments is that decisions about appropriate treatment are made by informed doctors not by uninformed patients [10]. The challenge for the payer is to manage or incentivise the healthcare provider to use cost-effective treatments, not to charge co-payments and expect patients to respond in a way that better aligns the costs and benefits of care to the health system.

However, pharmaceuticals are one of the few areas of healthcare service provision in which patient co-payments exist across Europe. Some countries, such as the United Kingdom, apply a small flat-rate charge per prescription item, although exemptions and total limits on expenditure apply. In other countries, such as France and Belgium, a percentage co-payment applies to some prescription items, with medicines for serious or life-threatening conditions being totally exempt from charges. Other countries such as Sweden operate an annual ceiling on the size of cumulative co-payments for all health services. Finally, in countries that operate therapeutic reference pricing, such as Germany and The Netherlands, patient co-payments apply in situations where the market price of the medicine is higher than the reference price. However, in practice this rarely applies as manufacturers tend to drop their price to the level of the reference price, in order to avoid loss of market share. The recent case of atorvastatin in Germany is an exception to this rule [11]. For a survey of co-payment systems in the European Union see Espin and Rovira [12]. A summary of their findings is set out in Table 1 below.

In a review of evidence on the efficiency of co-payments for pharmaceuticals in Europe, Thomson and Mossialos [13] concluded that European evidence was limited by poor data, with the more reliable evidence we discussed earlier originating from studies in North America, which, in their view, gave rise to questions about generalisability to a European context. However, there was evidence of some impact on utilisation, although non-vulnerable groups were insensitive to price. Co-payments did not result in sustained reductions in expenditure growth. The authors suggested that European governments could consider greater use of differential charges, both to encourage the substitution of cheaper or generic for more expensive or branded drugs

\footnotetext{
$\overline{3}$ Barer et al. [6] also argue that whilst co-payments may have some temporary effect of reducing costs to the third-party payer, over time co-payments will increase overall costs and hence income to producers. In their later review they point out that the design of the RAND study as an experiment meant it was not able to assess the impact on the health system over time of higher co-payments. They anticipate that suppliers would change behaviour in order to maintain incomes in the face of any fall in income arising from a fall in utilisation. Any macro-efficiency effect would be short term in duration.
}

Table 1 Overview of the application of co-payments in Europe

1. No co-pays: The Netherlands and Malta

2. Flat-rate: Austria, Italy, UK (with implicit ceiling: prescription pre-payment certificate)

3. Percentage rates: Belgium, France, Greece, Estonia, Finland (with annual ceiling), Latvia, Lithuania, Poland, Portugal, Slovakia, Slovenia and Spain

4. Uniform \%: Cyprus, Germany, Norway

5. Co-insurance, with $\%$ decreasing with accumulated expenditure over a given period and with a ceiling: Denmark and Sweden

6. Deductible: Ireland, Sweden

7. In many countries, there are specific exemptions for certain products as well as for some patient and socio-economic groups

Source Espin and Rovira [12]

and to stimulate the use of drugs with proven cost-effectiveness. Espin and Rovira [12] concluded that there were usually negative effects on access and equity unless user income and other considerations were taken into account. Cost sharing did not seem to discriminate according to therapeutic effectiveness and might delay the first contact with the healthcare system. They found that the Nordic countries had introduced sophisticated co-payment arrangements that seemed to them to adequately address some of these concerns by varying the amounts of the copayments, and using caps and time limits.

\section{Does the rise of cost-effectiveness thresholds and value- based pricing (VBP) mean we are in a new world?}

The role of co-payments for drugs has been recently debated, partly because of the general financial crisis facing many governments, but more importantly because of the escalating cost of medicines in some clinical areas, most notably cancer. This has led to restrictions of access to new medicines in some countries. In turn this has led to debates about (1) whether such restrictions, based on an implicit or explicit consideration of maximum societal willingness to pay for health technologies, really reflect individuals' preferences and (2) whether patients should be allowed to pay an additional amount to gain access to drugs that are excluded from public reimbursement. For example, even in the United Kingdom, a country traditionally opposed to patient co-payments, the health ministry initiated a scheme whereby individuals could pay 'top-up charges' in order to be treated with certain cancer medications that were not freely available within the National Health Service, although in this case the patient had to pay $100 \%$ of the cost of the medication [14].

If the role of patient co-payments for pharmaceuticals in Europe is to be reconsidered, it needs to be done within a policy framework that recognises the joint objectives of 
efficiency, equity and budgetary responsibility. Namely, it does not make sense to impose charges that greatly disadvantage individuals of a lower socio-economic status, or that deter individuals from seeking appropriate care which is cost-effective in the long run. Arguably we are now in or moving to an environment in which (1) healthcare payers are managing and incentivising providers to use costeffective treatments and (2) rationing is becoming more explicit, related to the third-party payer's 'willingness to pay' for health gain and related benefits.

In this context, we are moving between two different views of the world:

1. In the old world view the patient and the prescriber make the decision. Moral hazard and 'expenditure' issues are ones to be directed at the patient (advised by the prescriber) in decision-making. Considerations of equity and efficiency limit the usefulness of copayments

2. In the new world view the payer manages access using VBP. There is rationing. The payer seeks to determine utilisation through use of practice guidelines and outcomes/activity-based incentives to prescribers, given price and expected health gain and other net cost/benefit effects.

In the US, where co-payments are much higher for drugs and other healthcare services, Value-based insurance design (VBID) has been proposed [15] whereby low or zero co-payments are used for the treatments of known cost-effectiveness or where a patient is following a prescribed disease management pathway. Again the presumption is that the payer is driving utilisation and so moral hazard is not an issue. Indeed, the concern is to avoid co-payments reducing patient use of cost-effective treatment. ${ }^{4}$

In a world of VBP and payer guidelines, co-payment therefore becomes a route to enable patients to gain access to drugs that the healthcare system does not think are costeffective or which it thinks are cost-effective only at a lower price. In our view, health system efficiency is most likely to be found through the wider application of valuebased approaches to decisions on the pricing and reimbursement of medicines. A growing number of jurisdictions in Europe have been using assessments of the cost-

\footnotetext{
${ }^{4}$ We can note that Pauly and Blavin [16] have argued that VBID (and value-based cost sharing more generally) is consistent with the conventional moral hazard approach to using co-payments. Theory already suggests that co-payments should discriminate between disease areas and patients [1]. However, Pauly and Blavin are in effect recognising that co-payments have no role in improving efficiency if patients are not well informed and are not driving decision-making, i.e. the payer is more knowledgeable about incremental costs and benefits than the patient and is able to provide or deny treatment.
}

effectiveness of medicines in their decision-making. To date this has mostly focussed on reimbursement, leading to denial of access to some medicines through the public healthcare system or social health insurance package. However, some of the more recent proposals, such as those in the United Kingdom and Germany $[17,18]$ focus on the establishment of value-based prices for medicines in their various indications. In essence, the value-based price reflects the maximum societal willingness to pay, through the public healthcare system or statutory health insurance, for health technologies. Therefore, a possible role for copayments would be for individuals to pay extra for medicines whose market price is set higher than the value-based price.

National third-party payer systems inevitably trade-off diversity of population preferences with the equity benefits of operating a uniform package of benefits irrespective of income. In this situation, co-payment can become a way of recognising the heterogeneity of individual patient preferences [19] whilst respecting the need for public and privately funded health systems to restrict the treatments they can offer (or the prices they are willing to pay and by implication the treatments available if their willingness to pay is not accepted by the technology provider).

The use of co-payments in a world of VBP would also deal with one of the other negative consequences, for equity, of applying co-payments, namely information asymmetry or uninformed consumers. The process of establishing a value-based price, at least under the proposals being discussed in the United Kingdom, would generate a wealth of information about the relative merits and demerits of alternative medicines, in particular the extra benefits (if these exist) of those products whose market price is set higher than the value-based price. This should enable patients, with help from their physicians, to make more informed choices among the various treatments, some of which would be fully covered, some of which would carry a co-payment.

At first sight, this appears no different from the therapeutic reference pricing schemes operating in Germany and The Netherlands. The most substantive difference is that the reference price ( $a k a$ the value-based price) would not be set arbitrarily based on the price of the lowest-priced drug in the cluster, or an average price for the cluster. Rather it would be set as a result of a rigorous assessment of the value for money offered by different products, in relation to the societal willingness to pay applicable in the jurisdiction concerned. Therefore, equity of access would be maintained for all the medicines for which a value-based price can be agreed. On the other hand, if co-payments were also permitted, individuals whose preferences for health or health care differ from those embodied in the overall societal willingness to pay, could pay extra to gain 
access to medications that were not deemed to deliver enough social value for the cost.

\section{The residual challenges}

One potential downside of the proposed approach would be the administrative costs of collecting payments from patients. These costs are likely to vary from country to country and would be minimal in those jurisdictions already using therapeutic reference pricing, or other forms of co-payment.

However, the main challenge is to minimise the chances that allowing patient co-payments (partial payments for reference priced drugs or total payments for drugs not listed for certain indications) means that low-income people may be denied access to some drugs. The third-party payer system sets willingness to pay for health gain at whatever level it wants or can afford. That will act as the indirect price control. However, companies will make strategic pricing decisions around this. For example, if the payer's value-based price is far below the manufacturer's pricing expectations, the company may decide on a pricing strategy that relies on substantial numbers of patients being willing to make co-payments. In such a situation, the poor would be denied access to care whether they were unable to afford to make the co-payments.

On the other hand, the payer may be tempted to lower the willingness to pay threshold, and hence, the implied value-based price, in the knowledge that many patients would be willing to make the co-payments, rather than being denied access to care. (This would be analogous to an 'old world' use of co-payments as a method of offsetting the third-party payer's costs.) However, poorer patients, who may not be able to afford to make the copayments, would again be denied care.

However, if VBP is being applied in a rigorous and responsible fashion, both of these scenarios are unlikely. This is because the payer's willingness to pay threshold and the resulting value-based prices should be largely consistent with the values and preferences of the vast majority of the insured population. If this were the case, only a small minority of the population would be willing to make the co-payments. Indeed, if a substantial proportion of patients were willing to make the co-payments for a wide range of treatments, this would be a signal to the payer that the willingness to pay threshold was set too low in relation to community preferences.

\section{Conclusions}

In a world of VBP, it may be possible to use patient co-payments to deal with heterogeneity of preferences, without bearing the negative consequences for equity of access to care. Such a policy would give the signal to all parties that there would be guaranteed access to all medicines meeting the criteria used to establish a value-based price. Patients and physicians would be steered towards the therapies that deliver the most value for money, but there would be no restrictions on the access to other medicines for those willing to bear the co-payment.

Arguably evidence would be available to inform patient choice, meeting the main requirement of Barer et al. [6] for user charges to be useful. They conclude that 'We do identify some limited and very selective potential roles for direct charges. In each case, the charges must be for a welldefined product about which consumers have sufficient knowledge to make informed choices'.

We argue that such a role for co-payments recognises that healthcare choices within the third-party payer system are no longer at the discretion of the patient (the old case for using co-payments) but are driven by evidence-based clinical practice constrained by the need to use limited budgets on cost-effective treatments. Using co-payments for such cost-effective treatment risks reducing patient use of services the payer wants them to have (another 'old world' use of co-payments).

The success of our approach would depend on administrative feasibility and on the third-party payer's willingness to pay for health gain (as reflected in the value-based price) being set in a way that did not lead to large numbers of patients opting for treatments requiring co-payments.

\section{References}

1. Zeckhauser, R.J.: Medical insurance: A case study of the tradeoff between risk spreading and appropriate incentives. J. Econ. Theory 2(1), 10-26 (1970)

2. Chalkley, M., Robinson, R.: Theory and Evidence on Cost Sharing in Health Care: An Economic Perspective. Office of Health Economics, London (1997)

3. Manning, W.G., Newhouse, J.P., Duan, N., et al.: Health Insurance and the Demand for Medical Care. The RAND Corporation, Santa Monica, CA (1988)

4. Rubin, R.J., Mendelson, D.N.: A framework for cost sharing policy analysis. In: Mattison, N. (ed.) Sharing the costs of health: a multi-country perspective. Pharmaceutical Partners for Better Healthcare, Basel (1995)

5. Gerdtham, U.-G., Johanneson, M.: The impact of user charges on the consumption of drugs. Empirical evidence and economic implications. PharmacoEconomics 9(6), 478-483 (1996)

6. Barer, M.L., Evans, R.G., Stoddart, G.L.: User Charges, Snares and Delusions: Another Look at the Literature. The Premier's Council on Health, Well-being and Social Justice, Ontario (1994)

7. Lexchin, J., Grootendorst, P.: Effects of prescription drug user fees on drug and health services use and health status in vulnerable populations: a systematic review of the evidence. Int. J. Health Serv. 34(1), 101-122 (2004) 
8. Gibson, T.B., Ozminkowski, R.J., Goetzel, R.Z.: The effects of prescription drug cost sharing: a review of the evidence. Am. J. Manag. Care 11(11), 730-740 (2005)

9. Barer, M.L., Evans, R.G., Stoddart, G.L.: Controlling health care costs by direct charges to patients: snare or delusion? Occasional Paper 10, Ontario Economic Council, Toronto, 1979

10. Culyer, A.J.: Chisels or screwdrivers? A critique of the NERA proposals for the reform of the NHS. In: Towse, A. (ed.) Financing health care in the UK: A discussion of NERA's prototype model to replace the NHS. Office of Health Economics, London (1995)

11. Drummond, M.F., Jönsson, B., Rutten, F., Stargardt, T.: Reimbursement of pharmaceuticals: reference pricing versus health technology assessment. Eur. J. Health Econ. 12(3), 263-271 (2011)

12. Espin, J., Rovira, J. Analysis of differences and commonalities in pricing and reimbursement systems in Europe. Final Report. European Commission June 2007

13. Thomson, S., Mossialos, E.: Influencing demand for drugs through cost sharing. In: Mossialos, E., Mrazek, M., Walley, T. (eds.) Regulating pharmaceuticals in Europe: striving for efficiency, equity and quality. Oxford University Press for the European Health Observatory, Maidenhead (2004)

14. Jackson, E.: Top-up payments for expensive cancer drugs: rationing, fairness and the NHS. Mod. Law Rev. 73(3), 399-427 (2010)

15. Chernow, M.E., Rosen, A.B., Fendrick, A.M.: Value-based insurance design. Health Aff. 26(2), w195-w203 (2007)

16. Pauly, M.V., Blavin, F.E.: Moral hazard in insurance, valuebased cost sharing, and the benefits of blissful ignorance. J. Health Econ. 27(6), 1407-1417 (2008)

17. Department of Health: A new value-based approach to the pricing of branded medicines: a consultation. Department of Health, London, December 2010

18. Gerber, A., Stock, S., Dintsios, C.-M.: Reflections on the changing face of German pharmaceutical policy; how far is Germany from value-based pricing? Pharmacoeconomics 29(7), 549-553 (2011)

19. Danzon, P., Towse, A., Mulcahy, A.: Setting cost-effectiveness thresholds as a means to achieve appropriate drug prices in rich and poor countries. Health Aff. 30(8), 1529-1538 (2011) 